\title{
A Case Report with Research by Physical Medicine and Acupuncture Combination
}

\section{NM Kiron*}

Department of Acupuncture, Gonoshashthya Samaj Vittik Medical College and Hospital, India

Submission: July 28, 2018; Published: September 26, 2018

*Corresponding author: NM Kiron, Head of Department of Acupuncture Gonoshashthya Samaj Vittik Medical College and Hospital, Bangladesh, India, Tel: +8801911380937; Email: nurekiron58@gmail.com

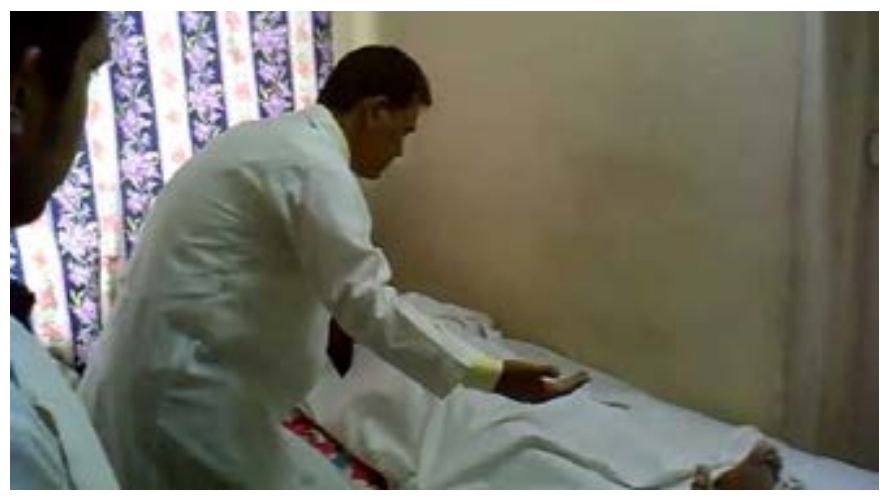

Introduction

A female patient age 82 yrs. Suffering from PLID. Shown by MRI report. compression on Neural roots by Intervertebral Disc Prolapses. Suggested by Neuro Surgeons and Orthopedics Surgeon need Laminectomy of that patient to remove Neural compressions. But patient unfit for General Anesthesia due to her Cardiac and Nephrological problems, came to me for remedy of that disease by alternative options.

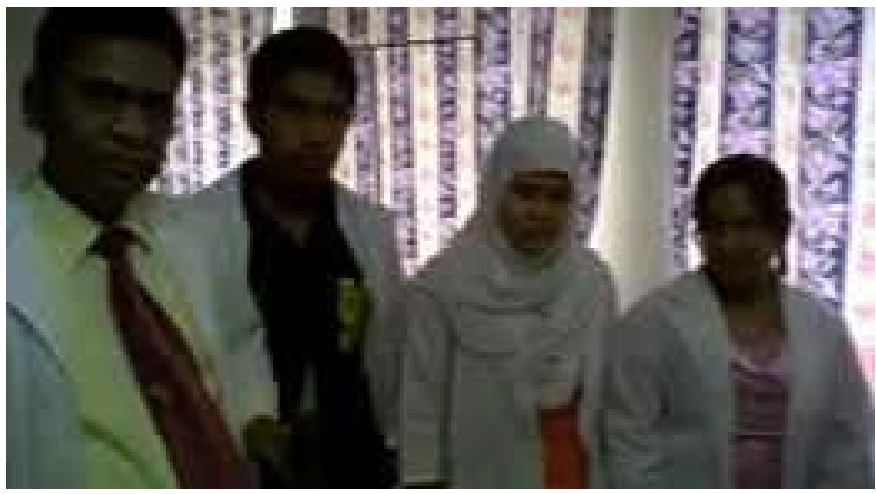

Video Showing problems by MRI film

\section{What is disc prolapses and herniation}

Common problems due to Disc Prolapses and herniation. Many patients suffer with back pain, legs pain or weakness of the lower extremities of muscle are diagnosed with a herniated disc. Some patients come to physicians for treatment of pain at both legs and backache with weakness. Some doctors diagnose for Lumbago Sciatica and some of them for PLID (Figure 1).

Figure 1: Examples of Disc problems 
Accordingly, patients are treated with Physiotherapy and Medicine at the primary stage. Due to application of pain killer Medicines, patients feel pain free at some extent, but it is revived again when medicine and physiotherapy are stopped. Gradually the case converted into Paraplegia. Most of neuro surgeons and orthopedics advised to the patients for Laminectomy to relief the instant pain (Figure 2).

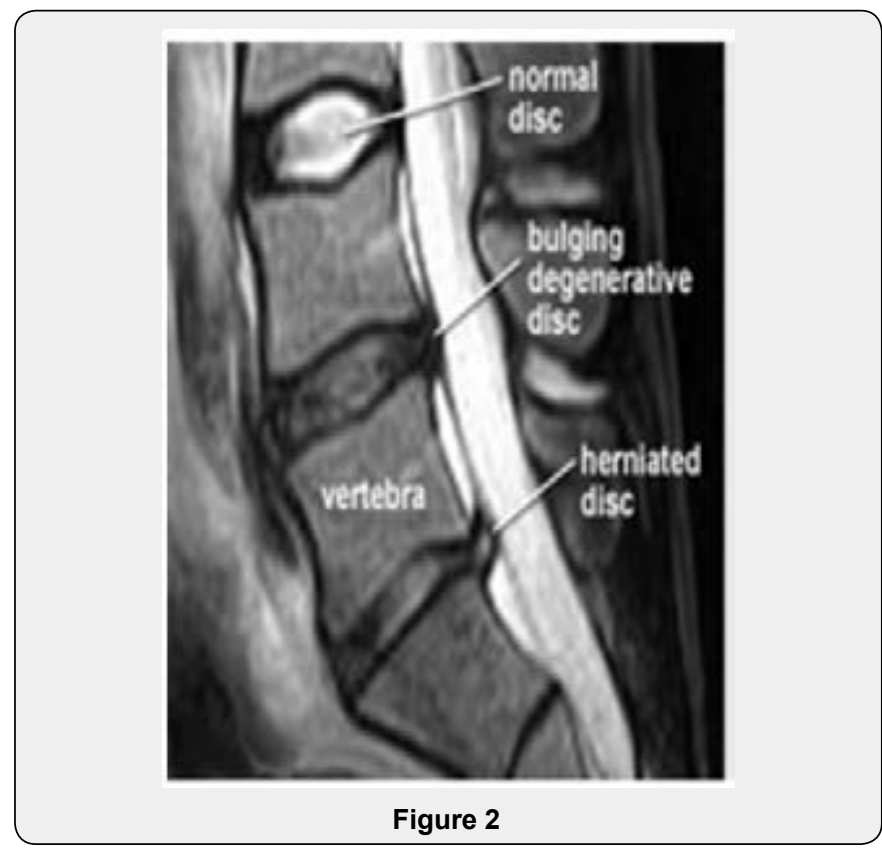

\section{Anatomy of Normal Lumbar Disc}

In between each of the 5 lumbar vertebrae is a disc, a tough fibrous shock absorbing pad. Endplates line the ends of each vertebrae and help hold each individual disc in place (Figure 3). Each disc contains a type like outer band (called the annulus fibrous) that encases a gel like substance (called the nucleus pulposus) (Figure 4). When a disc herniation occurs, the cushion that sits between the spinal vertebrae is pushed outside its normal position (Figure 5).

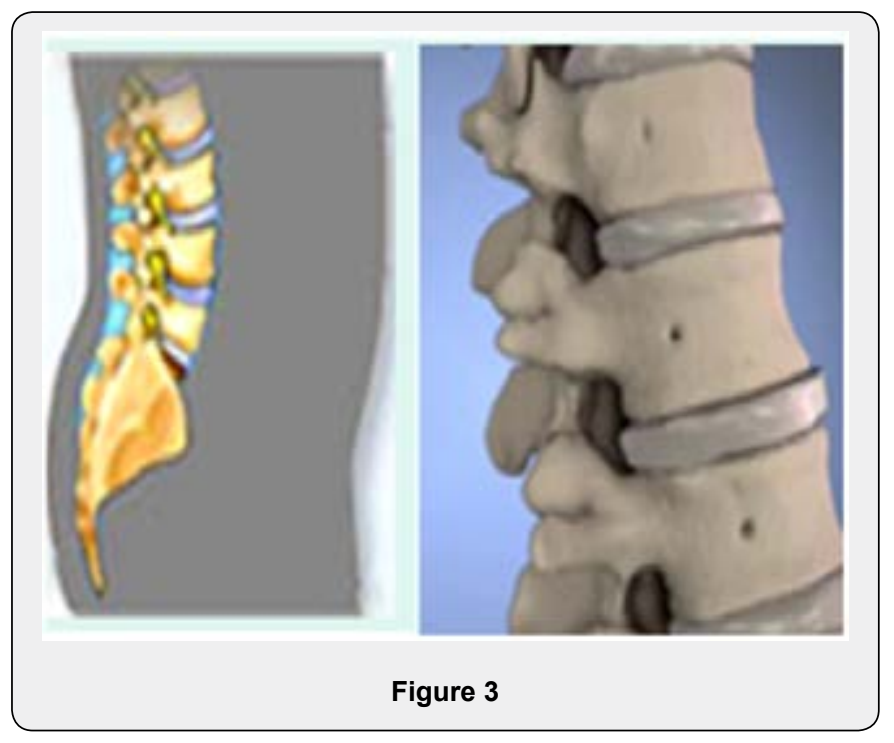

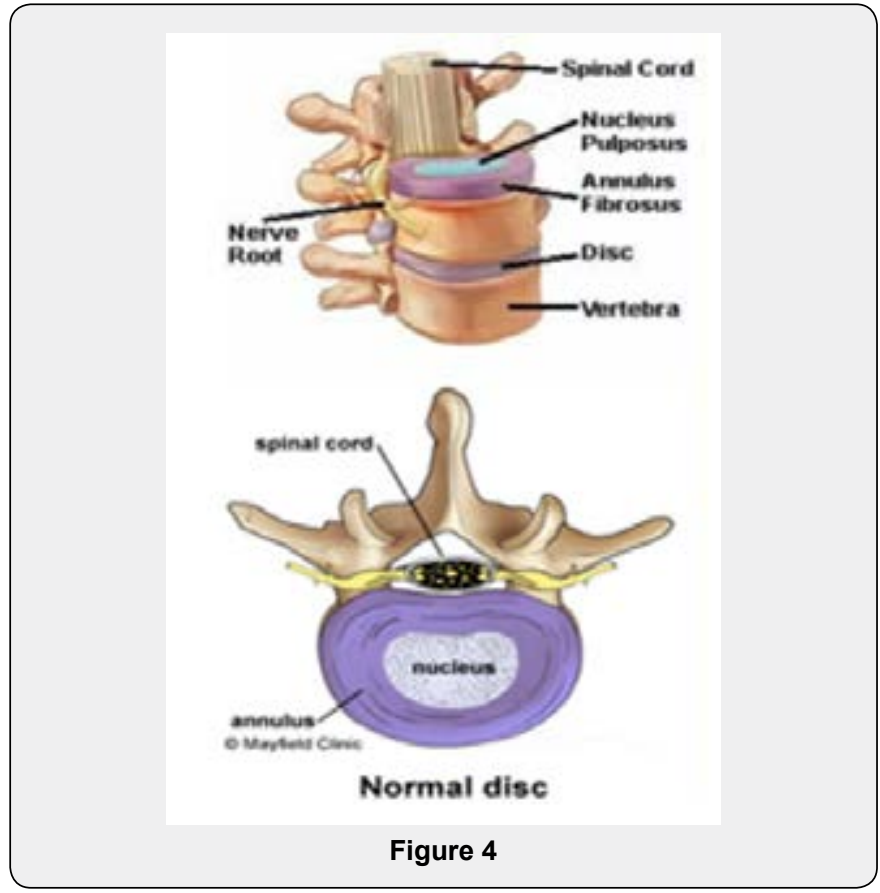

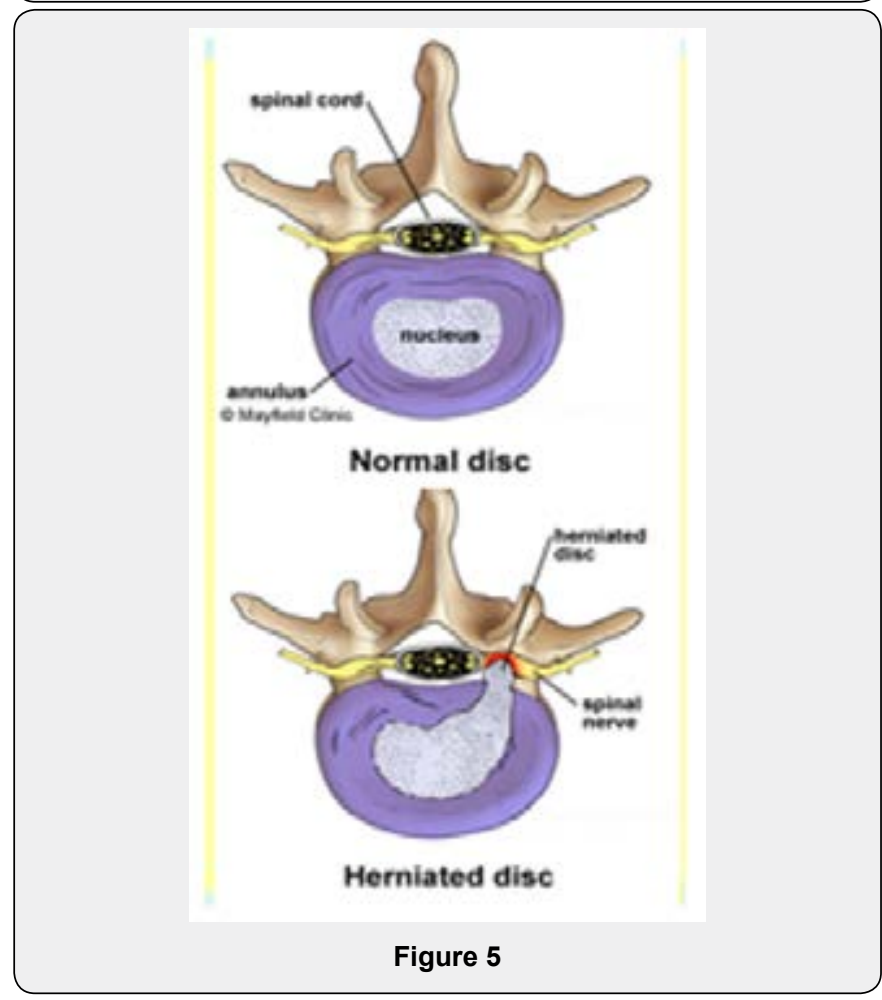

A herniated disc would not be a problem if it weren't for the spinal nerves that are very close to the edge of these spinal discs. Disc prolapses, or displacement mainly observed at the vertebra at the lumbar region. It occurs due to degenerative changes of bones at the old stage (Figure 6). Also, it may occur due to change of normal stage of cartilage for shortage of fluids or increase of protein in bone cells (Figure 7). As a result, then patients search for specialized doctors for correct diagnosis and after examination with Myllogram or MRI it ascertained that the cases are of Disc Prolapses and Herniation problems. 

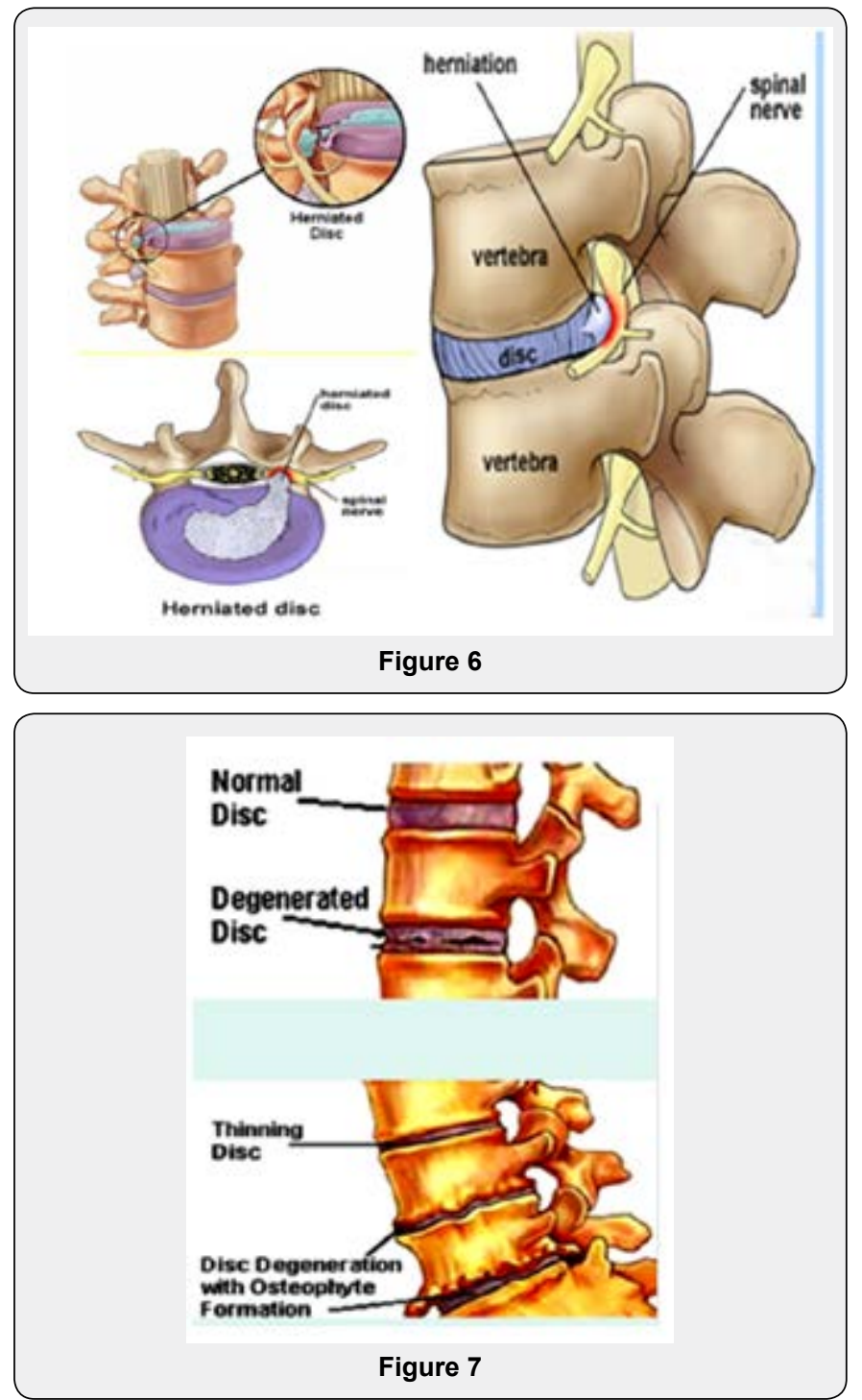

\section{Classifications}

There are different kinds of Disc Prolepses
a. Disc Degeneration
b. Disc Prolepses
c. Disc Extrusion
d. Disc Sequestration

\section{Causes}

a. Accident

When the herniated disc ruptures and pushes out, the nerves may become pinched. A herniated disc may occur suddenly in an event such as a fall or an accident or may occur gradually with repetitive straining of the spine.

\section{b. Spinal stenosis}

Often people who experience a herniated disc already have spinal stenosis, a problem that causes narrowing of the space around the spinal cord and spinal nerves. When a herniated disc occurs, the space for the nerves is further diminished, and irritation of the nerve results.

\section{Surgery for disc prolapse \& Herniation}

Laminectomy: If any bone and ligament is removed, then proper care to be taken for protection of the spinal nerves. When the disc herniation is found, the herniated disc fragment is removed. Depending on the appearance and the condition of the remaining discs. More disc fragments may be removed in the event of avoiding another fragment of disc from herniation in future. Once the disc has been cleaned out from the area around the nerves, the incision is closed, and bandage is applied.

Endoscopic Microdiscectomy: Recent techniques may allow a surgeon to perform a procedure called an endoscopic discectomy. In an endoscopic discectomy a surgeon uses special instruments and a camera to remove the herniated disc through very small incisions. Endoscopic Microdiscectomy is a procedure that accomplishes the same goal as a traditional open discectomy, to removing the herniated disc, but uses a smaller incision. Instead of actually looking at the herniated disc fragment and removing it, a surgeon uses a small camera to find the fragment and special instruments to remove it.

\section{Disadvantages of surgeries}

Laminectomy: Due to this type of surgery patients are lost muscle power, strengthen less of regional muscles and ligaments. It causes herniation again due to lack of normal functions of local herniated substances. Because, Local cells and tissues have the tendencies to return back to its original functions.

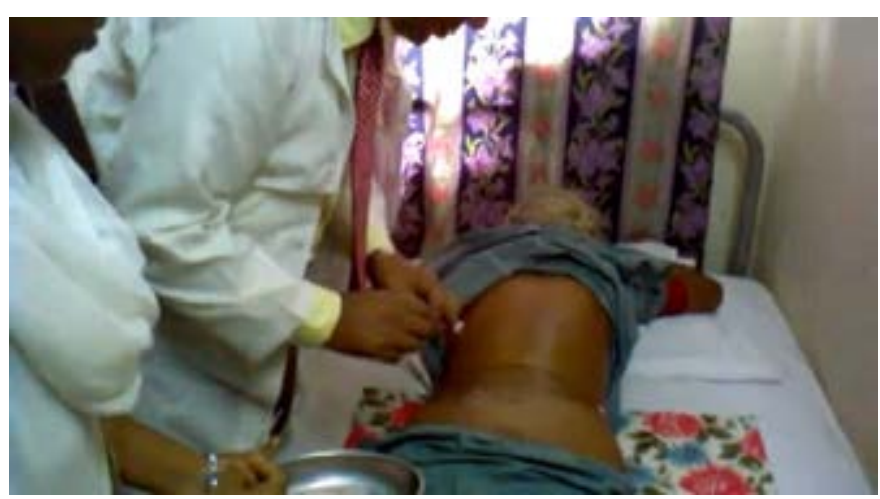

Video Acupuncturing to the Patient

\section{Advantages of Acupuncture}

Acupuncture Acts: But, in case of procedures done by acupuncture needling, the affected cells naturally regain the power to act by increased cell metabolic agents to normal functions. As a result, it is caused to reduce inflammation by producing of new cells.

\section{Mode of Therapeutic Actions}

Ultra sound Diathermy acts to reduce local inflammation and normalize the degeneration due to change of bone. Electro 
Acupuncture does the vital role for the cases of PLID. Acupuncture relaxes the superficial and deep muscles by the electrical deep stimulation through neural path way which helps pulling of local discs during traction, which may not be possible otherwise. Similarly, it strengthens weak muscles after traction therapies, for which, the discs dose not placed again due to strengthening of local muscles.
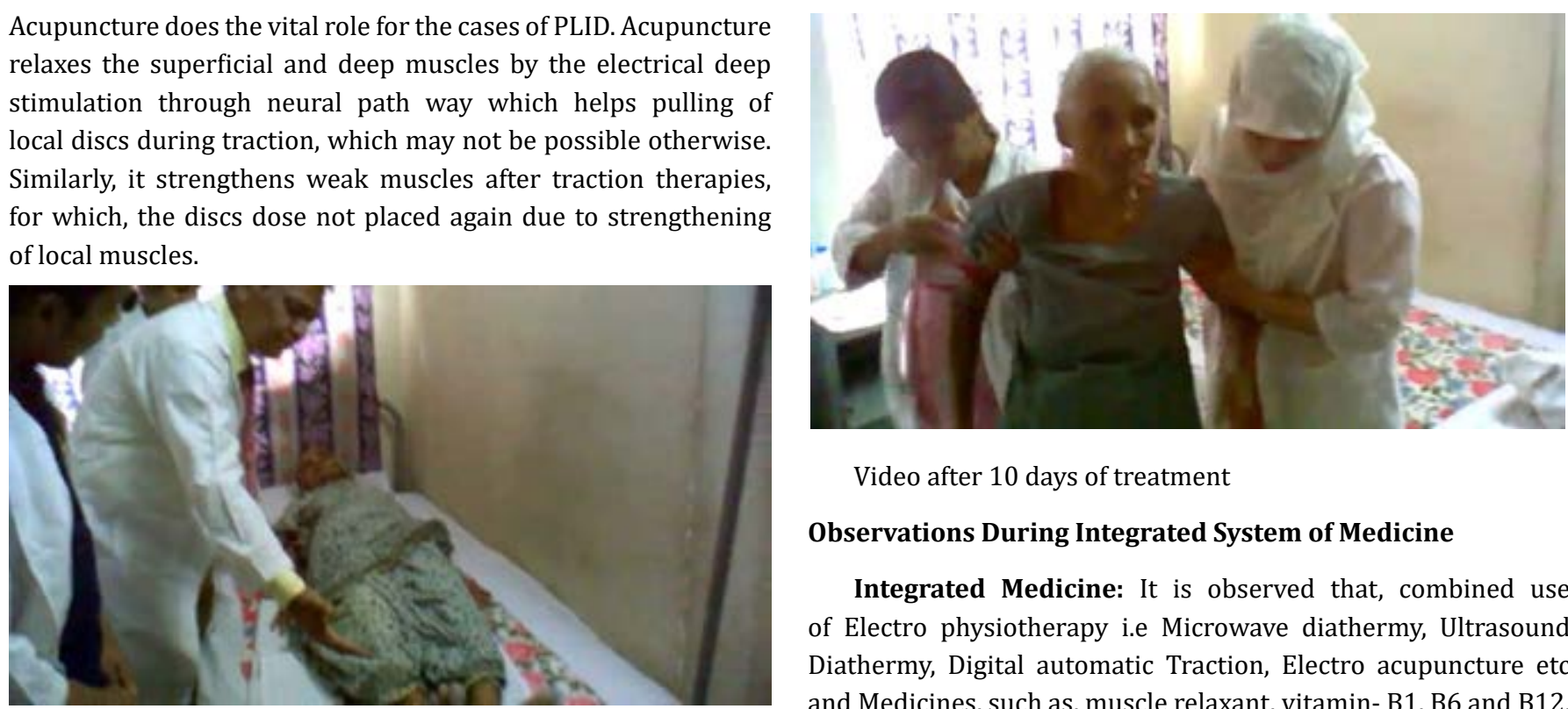

Video after 10 days of treatment

\section{Observations During Integrated System of Medicine}

Integrated Medicine: It is observed that, combined use of Electro physiotherapy i.e Microwave diathermy, Ultrasound Diathermy, Digital automatic Traction, Electro acupuncture etc and Medicines, such as, muscle relaxant, vitamin- B1, B6 and B12, Vitamin E are highly fruitful in that cases.

Video after 5 days treatment

\section{Benefits of Integrated System of Medicine}

Uses of Helpful Medicine during treatment offers muscle treatment, controls over muscle spasm of suffering areas. Also, vitamins supply nutrition to neural gate to receive proper acupuncture stimulation for the muscles, ligaments and nerves. Such a result would not be obtained from individual use of other treatments like Electro physiotherapy or Traction except Acupuncture stimulation.

Integrated medicine is the combination of Acupuncture Physiotherapy and Medicine. To get the successful result for disc prolapse and herniation, the integrated system of medicine is more better then Laminectomy or Micro Surgeries. Treatment under integrated system also includes Electro physiotherapy, Acupuncture and medicine.

\section{Information of Benefits}

The process of Integrated System of treatment is dealt with around 774 patients of PLID comparing the previous and post treatment MRI films during the period of January 08 to December 11 and observed the result of success is almost $82.08 \%$.

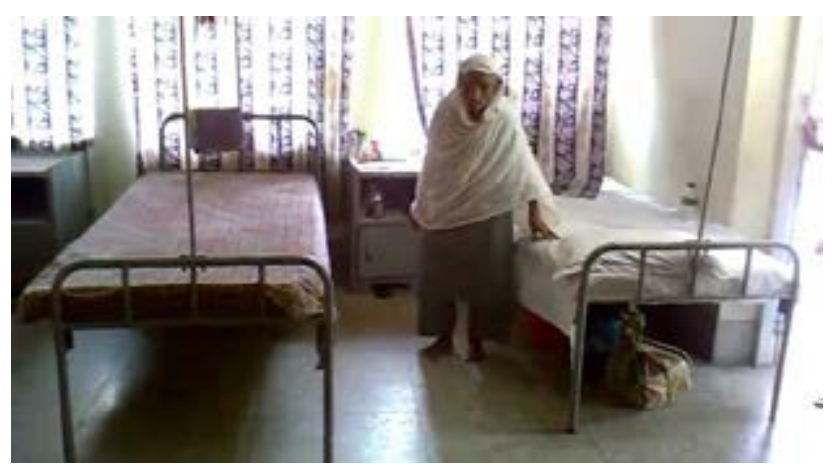

Video 23 days of treatment and patient has complete recovery.

Your next submission with Juniper Publishers will reach you the below assets

- Quality Editorial service

- Swift Peer Review

- Reprints availability

- E-prints Service

- Manuscript Podcast for convenient understanding

- Global attainment for your research

- Manuscript accessibility in different formats ( Pdf, E-pub, Full Text, Audio)

- Unceasing customer service

Track the below URL for one-step submission https://juniperpublishers.com/online-submission.php 